\title{
The Effects of Locus of Control, Agents of Socialization and Sport Socialization Situations on the Sports Participation of Women in Taiwan
}

\author{
Hsiu-Chin Huang ${ }^{1}$, Li-Wei Liu ${ }^{2}$, Chia-Ming Chang ${ }^{3}$, Huey-Hong Hsieh ${ }^{4, *}$ and Hsin-Chi Lu ${ }^{5}$ \\ 1 Physical Education and Arts School, Chengyi University College, Jimei University, Xiamen 361021, China; \\ op5166@yahoo.com.tw \\ 2 Department of Leisure Service Management, Chaoyang University of Technology, Taichung 41349, Taiwan; \\ ijofsrm@gmail.com \\ 3 Department of Physical Education, Health \& Recreation, National Chiayi University, Chiayi 62103, Taiwan; \\ gr5166@yahoo.com.tw \\ 4 Department of Leisure Management, Taiwan Shoufu University, Tainan 72153, Taiwan \\ 5 Department of Physical Education, Health \& Recreation, National Chiayi University, Chiayi 62103, Taiwan; \\ s1031021@mail.ncyu.edu.tw \\ * Correspondence: nancylin809@gmail.com; Tel.: +886-6-571-8888 (ext. 249)
}

Received: 8 March 2019; Accepted: 20 May 2019; Published: 23 May 2019

\begin{abstract}
Compared to men, the sports participation of women is lower, especially in the East. Not many studies have compared the impacts of locus of control, agents of socialization, and sport socialization situations on the sports participation of women. Hence, the purpose of this study is to explore the contributing factors which may promote the sports participation of women in Taiwan. To do this, 450 structured questionnaires were distributed to women in Chiayi, Taiwan, with an $89.3 \%$ return rate. The study found that internal locus of control, agents of socialization, and sport socialization situation had positive impacts on the sports participation of women. In line with these results, the study suggests the strengthening of the internal locus of control of women, making the best use of socialization agents, and improvement of sport socialization situations, in order to promote sports participation in women.
\end{abstract}

Keywords: personal character; agents of socialization; sports socialization situations; sports participation; women

\section{Introduction}

With a prevalence of sedentary lifestyles and poor dietary habits, many people suffer from obesity-induced diseases [1]. Participation in sports can promote health and help to avoid these diseases. For instance, Humphreys et al. [2] argued that regular exercise brings about the following advantages for human physical and mental health: improvement of physical structure composition, enhancement of physical function and activity, promotion of life tranquility and comfort, and increase of spiritual and intellectual activities. In addition, some studies [3,4] stated that sports participation can reduce depression and anxiety, avoid trait anxiety, and decrease mild and medium frustration. Therefore, regular engagement in sport activities can improve the physical state and promote mental health.

Woelfel and Haller [5] indicated that, in the process of sports socialization, there are three principal factors, including significant others (agents of socialization who can be imitated), sport socialization situations and opportunities (such as family, school, or community projects and facilities), 
and role-learning of general and personal attributes (such as personal character). Many related studies [6,7] have mentioned the effects of sports socialization and sports participation. Therefore, these agents of socialization gradually become the objects of study in research associated with the sociology of sport.

With a change in social structures and the rise of self-awareness in women, the participation of women in sport-related activities is more common than before, with some also participating in sports. For instance, in Taiwan, there are more and more female participants in running, cycling, or triathlon competitions [8]. In the past, the participation of women in sports has been rare. In the sports field, there have existed inequalities caused by traditional gender stereotypes. For instance, due to the gender stereotype of sports competence, opportunities for women to join in on sports activities and the capacity demonstrated have been limited [9]. Patriarchal society tends to define males as strong, active, and powerful beings and females as tender, passive, and obedient ones. This traditional norm is an invisible constraint for women and hinders their participation in sports [10,11].

However, practicing sports is an important tool for socialization. According to process of socialization, with the gender norm, the public has different views and standards regarding male and female sports participation, which results in the female gender role and the consequent obstacles. The process of sports socialization and the sources of its effect on socialization are extremely diverse. It influences the process for women to approach sports and leads to different personalities and behavior $[12,13]$. Some previous studies have revealed that the percentage of female participation in sports was low, less than males $[14,15]$. Hence, knowing the driving and hindering factors influencing the participation of women in sports may help to promote the engagement of women in sport. In this study, we investigated 450 female subjects in Taiwan using a structured questionnaire to explore the effects of personal character, agents of socialization, and sport socialization situations on the sports participation of women. We hope these findings can contribute to the promotion of the participation of women in sports and to further understand the inner and outer drivers of and barriers to female engagement in sports.

\section{Research Hypotheses}

\subsection{The Relationship between Locus of Control and Sports Participation}

According to Rotter's social learning theory [16], locus of control is the belief to which people determine whether or not they get reinforced in life. People can be classified along a continuum, from very internal to very external. A person with a very internal locus of control believes the responsibility of whether he or she gets reinforcement lies with himself/herself. On the other hand, people with an external locus believe the reinforcements in life are controlled by chance, opportunity, destiny, or by powerful others. As Rotter pointed out, the locus of control is a generalized expectancy; it can predict the behavior of people across different situations. Namely, their behavior can be affected by the environment and situations they encounter. For example, Arslan et al. [17] investigated 514 college students aged 18-27 and found that students with a higher internal locus had significantly lower trait anxiety scores than those with a higher external locus of control. In relation to body image, Chang and Tsai [18] argued that the locus of control is the key factor determining the body image of an individual. Furnham and Grecves [19] also argued that people with a higher internal locus of control have higher intention to improve their body image. In comparison to those with externals, internals are happier and more satisfied with their body image [20]. According to Leonard [21] and Snyder [22], the unique social, individual, and environmental learning and experiences of an athlete results in their progress in the sport field. Therefore, we propose the following:

Hypothesis 1 (H1): The participation of women in sports is influenced by their locus of control. 


\subsection{The Relationship between Agents of Socialization and Sports Participation}

Socialization is a process in a group which teaches each member the rules (social norms) and skills to participate in that society. Agents who are key figures in enforcing social rules are called socializing agents [23]. Agents of socialization include family, institutional agents (school, workplace, and government), friends, the community, and mass media. Specifically, after adolescence, an institutional agent has much less influence on the sports participation of individuals and, as the interest of our study is related to the sports participation of female adults, we have excluded the effect of institutional agents. Therefore, the agents of socialization considered in the study include family, friends, mass media, and the community. Some studies have explored the effect of agents of socialization on sports participation. As for family, family encouragement and support for participation in sports would reinforce the attitude towards sports of an individual, along with participation motivation and behavior [24,25]. There is significant correlation between the participation motivation and the significant others of athletes [26]. For example, the intention of an individual to participate in sports is influenced by the support and interaction with school administrators, physical education teachers, coaches, classmates, or sports teams [27]. As for friends, Lin et al. [28] studied female teachers who joined in table tennis and found that the affective support and belonging of their friends could satisfy their sense of achievement and self-realization, which was the drive for their continuity in table tennis. As for community, in Taiwan, people can access public school gymnasiums (such as swimming pools, badminton courts, basketball courts, and so on) after-school hours and some schools even rent them out to residents, as long-term sports places, by contract in off-peak hours (after-school hours) [29]. The accessibility and convenience of sports fields in the community may also increase sports participation intention in the community. As for mass media, Chang [30] stated that, by transmission of media, many people were profoundly affected. For instance, TV broadcasts, newspaper reports, and related sports magazines or websites provide knowledge associated with sports or information related to sports games, as well as the creation of sports stars and the introduction of sports appliances. These all influence individual sports participation behaviors. Based on a previous literature review, agents of socialization are key factors in individual sports participation. Thus, this study proposes the following:

Hypothesis 2 (H2): Family has a significant impact on the sports participation of women.

Hypothesis 3 (H3): Friends have a significant impact on the sports participation of women.

Hypothesis 4 (H4): The community has a significant impact on the sports participation of women.

Hypothesis 5 (H5): Mass media has a significant impact on the sports participation of women.

\subsection{The Relationship between Sport Socialization Situations and Sports Participation}

Common social organizations or social factors of socialization learning refer to socio-economic status, background, location, and facilities [31]. Sport socialization situations refer to the convenience of sport facilities for a person to participate in sports. Chien [32] argued that the sports environment can enhance sports behavior and environmental demands, including accessibility, extensity, safety, support, and aesthetics. Yang et al. [33] found that community sports facilities are important factors for public participation in sports. For instance, Sallis and Kerr [34] proposed six items of community design which influence physical activity level, including community connectivity, density, land-use mix, aesthetics, safety (or perceived safety), and public transit. Reduction of distance between the location of an individual and the destination, to allow them to walk or ride a bike instead of driving a car and increasing their visit intention by having a safe and aesthetic environment reinforces their physical activity in daily lives. Therefore, this study proposes the following: 
Hypothesis 6 (H6): Sport socialization situations have a significant impact on the sports participation of women.

\section{Methods}

\section{Participants}

Female adults, over 20 years old, were invited to participate in our study in Chiayi City and Chiayi County in Taiwan. A structured questionnaire was distributed in markets, shopping malls, department stores, post offices, and banks in Chiayi County and City where women frequently appeared. A total of 450 questionnaires were distributed. Before questionnaire distribution, subject consents were acquired. A total of 402 valid questionnaires were retrieved, with a valid return rate of $89.3 \%$. Among all participants, $71.9 \%$ were married. The descriptive statistics also show that the most prominent educational level of respondents (46\%) was a Bachelor degree. In $97 \%$ of respondents, the monthly income was under US\$2600; most were between 31-40 (34.6\%); most had two children (35.1\%); 374 subjects $(79.0 \%)$ had full-time job; 84 subjects (20.9\%) participated in sports clubs; and 90 subjects $(22.4 \%)$ had participated in school sports teams in recent years (see Table 1 for details).

\section{Measurements}

\subsection{Locus of Control Scale}

The extent of the locus of control of an individual can range from an extremely internal to extremely external. To measure the locus of control of respondents, we used a four-item 'internal locus of control scale", designed by Rotter [16], using a Likert's five-point scale, ranging from " $1=$ strongly disagree" to " 5 = strongly agree" (see Appendix A for details). If an internal locus of control was manifest, the total score is above 12. On the contrary, people with a higher external locus of control will obtain a lower score. Cronbach's $\alpha$ of the total scale was 0.724 .

\subsection{Agents of Socialization Scale}

The scale design for agents of socialization was designed upon the related literature and the "sports socialization scale", designed by Chen et al. [27], which was revised, according to the research subjects. There were four dimensions: "family", "friends", "community", and "mass media", including 14 items. Likert's five-point scale was used, ranging from " $1=$ strongly disagree" to " $5=$ strongly agree" (see Appendix B for details). Cronbach's $\alpha$ for family was 0.821 ; for friends was 0.746 ; for community was 0.704 ; for mass media was 0.794 ; and for the total scale was 0.849 .

Table 1. Description of the demographic variables of the participants.

\begin{tabular}{|c|c|c|c|c|c|c|c|}
\hline Variables & Groups & $\mathbf{N}$ & $\%$ & Variables & Groups & $\mathbf{N}$ & $\%$ \\
\hline \multirow{6}{*}{ Education Level } & Elementary school & 5 & 1.2 & \multirow{2}{*}{ Marital status } & Married & 289 & 71.9 \\
\hline & Junior high school & 9 & 2.2 & & Unmarried & 113 & 28.1 \\
\hline & Senior high school & 57 & 14.2 & \multirow{5}{*}{ Monthly income (USD) } & No income & 15 & 3.7 \\
\hline & Junior college & 75 & 18.7 & & Between $\$ 1$ and $\$ 650$ & 25 & 6.2 \\
\hline & College & 185 & 46.0 & & Between $\$ 650$ and $\$ 1300$ & 184 & 45.8 \\
\hline & Graduate school & 71 & 17.7 & & Between $\$ 1300$ and $\$ 2600$ & 166 & 41.3 \\
\hline \multirow{5}{*}{ Age } & Between 20 and 30 years old & 77 & 19.2 & & Exceeded $\$ 2600$ & 12 & 3.0 \\
\hline & Between 31 and 40 years old & 139 & 34.6 & \multirow{4}{*}{ Number of children } & No children & 131 & 32.6 \\
\hline & Between 41 and 50 years old & 130 & 32.3 & & One & 62 & 15.4 \\
\hline & Between 51 and 60 years old & 44 & 10.9 & & Two & 141 & 35.1 \\
\hline & Exceeded 61 years old & 12 & 3.0 & & Three or more than three & 68 & 16.9 \\
\hline \multirow{2}{*}{ Full time job } & Yes & 374 & 93.0 & \multirow{2}{*}{ Participate in sport clubs } & Yes & 84 & 20.9 \\
\hline & No & 28 & 7.0 & & No & 318 & 79.1 \\
\hline \multirow{2}{*}{$\begin{array}{l}\text { Participation in school sports } \\
\text { teams in past years of study }\end{array}$} & Yes & 90 & 22.4 & & & & \\
\hline & No & 312 & 77.6 & & & & \\
\hline
\end{tabular}




\subsection{Sport Socialization Situations Scale}

The scale for sport socialization situations was designed using a revision based on the items of the environmental facility scale of Chien [32]; including "safety", "extensity", "convenience", "atmosphere", and four items, such as "locations of sports places I frequently visit are safe" and "locations of sports places I frequently visit are easy to reach" (See Appendix C for details). Likert's five-point scale was used, ranging from " $1=$ strongly disagree" to " $5=$ strongly agree". Cronbach's $\alpha$ for the total scale was 0.858 .

\subsection{Level of Exercise Participation}

Level of exercise participation was estimated using Fox's Exercise Engagement Scale [35]. The scale was comprised of three items, in terms of frequency, intensity, and duration. As for frequency, respondents were asked "How often do you do exercise in a week?", ranging from " $1=$ less or equal to once" to " $5=$ equal to or more than five times". As for intensity, respondents were asked "On average, how did you feel after working out?", ranging from " $1=$ not tired at all" to " $5=$ exhausted". As for duration, respondents were asked "On average, how many minutes did you exercise each time?", ranging from " $1=$ less than $30 \mathrm{~min}^{\prime}$ to " $5=$ over $120 \mathrm{~min}$ " (See Appendix D for detail). To estimate the level of exercise participation, we used Fox's formula as follows:

$$
\text { Level of exercise participation }=\text { frequency } *(\text { duration }+ \text { intensity }) .
$$

The higher the figure was, the higher the level of exercise participation. Cronbach's $\alpha$ of the total scale was 0.858 .

\subsection{Data Analysis}

Six hypotheses were developed in this study and data analysis was carried out using partial least squares (PLS). PLS is similar to structural equation modeling (SEM) and measures the correlation of constructs [35,36]. There are many statistical software packages that enable users to use PLS. Warp PLS 5.0, developed by Kock [37], was used in the present study.

\section{Results}

\subsection{Descriptive Statistics}

Table 2 presents the summary statistics of all construct variables. Among all prediction variables, locus of control was the highest, indicating most subjects had a high internal locus of control. The second highest was family, indicating that the family support of participants was high $(\mathrm{M}=3.80, \mathrm{SD}=0.65)$. Sport socialization situations was the third highest, indicating that the perception of sport socialization situations was high $(\mathrm{M}=3.77, \mathrm{SD}=0.65)$. As for sports participation, compared to the scale score range (2-50), the statistics showed that the level of sports participation was very low $(M=9.63, S D=4.76)$.

Table 2. Descriptive statistics of all construct variables.

\begin{tabular}{cccc}
\hline Variables & Mean & Standard Deviation & Score Range \\
\hline LC & 4.11 & 0.57 & $1-5$ \\
FA & 3.8 & 0.65 & $1-5$ \\
FR & 3.53 & 0.66 & $1-5$ \\
COM & 3.04 & 0.78 & $1-5$ \\
MM & 3.07 & 0.69 & $1-5$ \\
SSS & 3.79 & 0.65 & $1-5$ \\
SP & 9.63 & 4.76 & $2-50$ \\
\hline
\end{tabular}

Note: LC: locus of control; FA: family; FR: friend; COM: community; MM: mass media; SSS: sport socialization situations; SP: sport participation. 
Among the background variables for women about sports participation, no significant differences were found between marriage, level of education, age, the number of children, or whether they had a full-time job. There were significant differences in monthly income, whether they were members of sport clubs at the time of the study, and previous experience in participating in school sport teams during schooling.

\subsection{The Structural Model and Hypothesis Testing}

An evaluation of the structural model is used to examine the six hypothesized relationships. The test results are shown in Table 3 and Figure 1 . In line with the value and significance of the path coefficients, locus of control $\left(\beta_{1}=0.19, p<0.05\right)$, family $\left(\beta_{2}=0.10, p<0.05\right)$, friends $\left(\beta_{3}=0.29\right.$, $p<0.05)$, and sport socialization situations $\left(\beta_{6}=0.34, p<0.05\right)$ appear to have positive impacts on sport participation, while community $\left(\beta_{4}=0.04, p>0.05\right)$ and mass media $\left(\beta_{5}=0.05, p>0.05\right)$ do not.

Table 3. Path results for the structural model.

\begin{tabular}{llll}
\hline Hypothesis & Path & Path Coefficient & $p$-Value \\
\hline H1 & LC $\rightarrow$ SP & $0.19\left(\beta_{1}\right)$ & $<0.05^{*}$ \\
H2 & FA $\rightarrow$ SP & $0.10\left(\beta_{2}\right)$ & $<0.05^{*}$ \\
H3 & FR $\rightarrow$ SP & $0.29\left(\beta_{3}\right)$ & $<0.05^{*}$ \\
H4 & $\mathrm{COM} \rightarrow$ SP & $0.04\left(\beta_{4}\right)$ & $>0.05$ \\
H5 & MM $\rightarrow$ SP & $0.05\left(\beta_{5}\right)$ & $>0.05$ \\
H6 & SSS $\rightarrow$ SP & $0.34\left(\beta_{6}\right)$ & $<0.05^{*}$ \\
\hline
\end{tabular}

Note: * significant; LC: locus of control; FA: family; FR: friends; COM: community; MM: mass media; SSS: sport socialization situations; SP: sport participation.

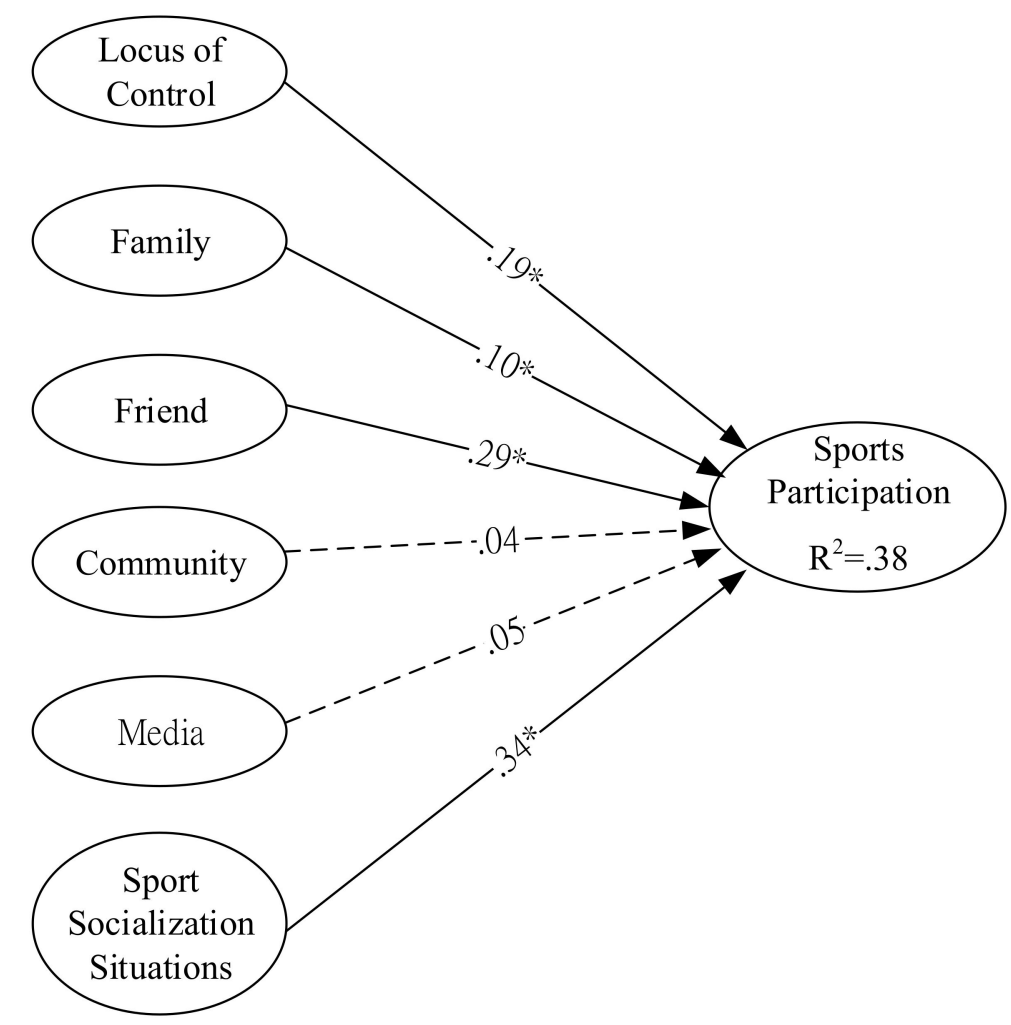

Figure 1. Structural equation modeling (SEM) results of the standardized model parameter estimation. * $p<0.05$; solid line: significant; dashed line: non-significant.

Based on the path estimates, it was found that sport socialization situations was the most important predictor of sport participation (standardized path coefficient $=0.34$ ), the second most important 
predictor was friends (standardized path coefficient $=0.29$ ), and the third most important was locus of control (standardized path coefficient $=0.19$ ).

In addition, the six variables, all together, explained a $38 \%$ variance in the sports participation of women $\left(R^{2}=0.38\right)$.

\section{Discussion}

According to the statistical results presented above, it seemed that the model examined in the current study was able to reach an acceptable level, in the terms of predictive power $\left(R^{2}=0.38\right)$. In relation to the path coefficient analyses, locus of control was found to have predicting power with a coefficient of 0.19 , which indicated that women with a higher internal locus of control had a higher sport participation level. This result provides support for the significant effect of personal character on sports behavior. Crothers et al. [38] argued that people who lack internal control tend to encounter emotional exhaustion and discomfort. On the other hand, people with internal control are less stressful. In relation to the sports field, research found team players had higher positive perception of the leadership of a coach when the coach had internal control [39]. In a study of university students in table-tennis courses related to locus control, the study found that the internal control-oriented subjects who learned difficult work first had more accurate performance than the external control-oriented ones [40-48]. In summary, people with a higher internal locus of control had better performance in the sports-learning process and were less frustrated. They believed that they could make progress and perform well with effort. Hence, reinforcement of the internal locus of control for women is one of future directions for promoting the sports participation of women.

The effects of friends and family on sports participation of women are significant and positive. This suggests that sports participation levels can be enhanced by friends and family. These results were supported by previous findings. For example, Coleman et al. [41], who interviewed seventy-five 15-19 year-old young British women, realized that the friendship group was the most critical factor in sports participation. Young et al. [42] argued that, when sports are supported by friends, the interactive quality and pleasure are enhanced. Sharma et al. [43] stated that family member support reinforced the sports participation of African American women in their leisure time. Therefore, the company of friends and the encouragement of family member increase the sports participation intention of women. On the other hand, the effects of the community and mass media on sports participation of women were not significant. It seemed that support from the community (nearby sport field, sport-related events, and the company of neighbors) for sports participation was not strong enough. Additionally, support from the mass media was not significant, indicating the necessity of posting more female-oriented sports-related agenda, events, and advertisements.

Female sport socialization situations significantly and positively influence sports participation. This is consistent with previous research findings, which argued that convenience of environment for sports socialization significantly influenced sports participation. For instance, people tend to practice running and walking when there is park in the neighborhood. Dirtiness in sports places, such as too much trash and the excrement of animals, lowers their sports intention [49]. Vojnovic [45] stated that, when the distance to sports place was less than $0.8 \mathrm{~km}$, it encouraged those who could walk to the place to practice exercises; and sports places with distances less than $5 \mathrm{~km}$ attracted bike riders. Liu et al. [46] stated that the spatial design of sports places and sports facilities influenced intention for sports participation. For instance, when the lighting of sports places is sufficient and the width of running tracks is appropriate, participants perceive comfort and safety, which, in turn, can attract people to go there for exercise. Duncan [47] suggested that the crime rate and the problem of stray dogs in sports places negatively affected intention of sports participation. Therefore, we suggest the enhancement of environmental atmosphere, convenience, and safety to promote the sports participation of women. 


\section{Recommendations}

Based on the findings of this study, for women in Chiayi County and City, sport socialization situations are the most important key factor for the sports participation of women; the second most important factor is friends (as agents of socialization); the third most important is locus of control; and the fourth is family (as agents of socialization).

As for sport socialization situations, we suggest that related governmental or administrative sectors can plan sports places for women, to allow them to have comfortable and safe sports environments. In addition, convenience is one of the key factors. If sports places are too distant, the women will not be motivated. Therefore, sports places for women can be installed in the downtown or surrounding areas, to enhance convenience of location and create a positive and comfortable sports environment and atmosphere. In addition, they can plan sports programs exclusively for women, such as running and sports meet competitions, to reinforce their sports participation.

As for agents of socialization, we suggest women to practice sports with family members or friends, and change shopping or afternoon-tea time into mountain climbing or hiking time; not only to enhance their physical strength, but also to increase their pleasure in sports and techniques.

Locus of control is another factor affecting the sports participation of women. Therefore, we recommend the government to promote equal education opportunities and encourage women to engage in sports, to increase the internal locus of control of women toward sports participation.

The results of this study revealed that "community" and "mass media", as agents of socialization, are not associated with the sports participation of women. This result differs from some related research [48,49]. It is suggested that, in future research, the reason for this should be explored, in order to further explore the effects of personal character and sports agents of socialization on the sports participation of women and to compare the cultural differences among nations.

Author Contributions: Conceptualization, H.-C.H. and C.-M.C.; Methodology, H.-C.H. and C.-M.C.; Software, H.-H.H. and C.-M.C.; Validation, H.-C.H., C.-M.C. and L.-W.L.; Formal Analysis, C.-M.C.; Investigation, H.-C.L.; Resources, H.-C.H.; Data Curation, C.-M.C.; Writing-Original Draft Preparation, H.-H.H.; Writing-Review \& Editing, H.-H.H., C.-M.C., L.-W.L. and H.-C.H.; Visualization, H.-C.H; Supervision, C.-M.C.; Project Administration, L.-W.L.

Funding: This research was supported by the Ministry of Science and Technology, Taiwan (MOST 105-2410-H-415 -011).

Conflicts of Interest: The authors declare no conflicts of interest

\section{Appendix A}

Table A1. Measurement of locus of control.

If I set a reasonable goal, I am likely to achieve it with hard work and commitment.

The things that happen in peoples' lives are of their own doing.

Using good interpersonal skills can help get people to like me.

How I treat people determines how they treat me. 


\section{Appendix B}

Table A2. Measurement of agents of socialization.

\begin{tabular}{|c|c|}
\hline Construct & Item \\
\hline Family & $\begin{array}{l}\text { The members of my family always encouraged me to participate in sports activities. } \\
\text { I always received compliment on doing exercises from my family members. } \\
\text { My family members were always very supportive of my sport activities. } \\
\text { My family and I always participate in sports together. }\end{array}$ \\
\hline Friend & $\begin{array}{l}\text { Friends always encouraged me to participate in sports. } \\
\text { Friends and I always participate in sports together. } \\
\text { Associations with friends in sports made me feel good. }\end{array}$ \\
\hline Community & $\begin{array}{l}\text { There are enough sports fields for me to do sports nearby my place. } \\
\text { There are many sports-related events nearby my place. } \\
\text { I enjoyed doing sports with my neighbors. }\end{array}$ \\
\hline Mass media & $\begin{array}{l}\text { Ads related to sports on media always increased my desire for sports participation. } \\
\text { Seeing famous athletes on media always increased my desire for sports participation. } \\
\text { I am very interested in sports-related news. } \\
\text { I acquired sports skills through media. }\end{array}$ \\
\hline
\end{tabular}

\section{Appendix C}

Participants were asked to rate the sports field they frequently visited.

Table A3. Measurement of sport socialization situations.

Very safe
Very comfortable
Easy to approach
Great exercise atmosphere

\section{Appendix D}

Table A4. Measurement of level of exercise participation.

\begin{tabular}{l}
\hline Frequency: On average, how many times you do exercise in a week? \\
1: None 2: 1-2 times 3: 3-4 times 4: 5-6 times 5: more than 7 times \\
\hline Intensity: On average, how did you feel after workout? \\
Not tired at all 2 . Not tired 3. Somewhat tired 4. Tired 5. Very tired. \\
Duration: On average, how many minutes did you exercise each time? \\
1: less than 30 min $2.31-60$ min 3. $61-90$ min $4.91-120$ min 5. More than 121 min. \\
\hline
\end{tabular}

\section{References}

1. Hsieh, H.H.; Chang, C.M.; Liu, L.W.; Huang, H.C. The Relative Contribution of Dietary Habits, Leisure-Time Exercise, Exercise Attitude, and Body Mass Index to Self-Rated Health among College Students in Taiwan. Int. J. Environ. Res. Public Health 2018, 15, 967. [CrossRef] [PubMed]

2. Humphreys, B.R.; McLeod, L.; Ruseski, J.E. Physical activity and health outcomes: Evidence from Canada. Health Econ. 2014, 23, 33-54.

3. Guo, Y.; Shi, H.; Yu, D.; Qiu, P. Health benefits of traditional Chinese sports and physical activity for older adults: A systematic review of evidence. J. Sport Health Sci. 2016, 5, 270-280. [CrossRef]

4. Oja, P.; Titze, S.; Kokko, S.; Kujala, U.M.; Heinonen, A.; Kelly, P.; Koski, P.; Foster, C. Health benefits of different sport disciplines for adults: Systematic review of observational and intervention studies with meta-analysis. Br. J. Sports Med. 2015, 49, 434-440. [PubMed] 
5. Woelfel, J.; Haller, H.O. Significant others, the self-reflexive act, and the attitude formation process. Am. Sociol. Rev. 1971, $36,74-87$.

6. Coakley, J. Sport and Socialization. Exerc. Sport Sci. Rev. 1993, 21, 169-200. [CrossRef] [PubMed]

7. Coakley, J. Sports in Society: Issues and Controversies; McGraw-Hill: New York, NY, USA, 2004.

8. Kuo, P.-K.; Li, F.-E. The Research of the motivation, level of involvement and recreational benefits of the super triathlon participants. Sports Tour. Res. 2015, 4, 11-28.

9. Boyle, R.; Haynes, R. Power Play: Sport, the Media and Popular Culture; Edinburgh University Press: Edinburgh, UK, 2009.

10. Trolan, E.J. The impact of the media on gender inequality within sport. Soc. Behav. Sci. 2013, 91, $215-227$.

11. Senne, J.A. Examination of Gender Equity and Female Participation in Sport. Sport J. 2016, 19, 1-9.

12. Spaaij, R.; Anderson, A. Parents or peers: Which is it? Sport socialization and team identification in Australia: A rejoinder to Melnick and Wann. Int. Rev. Sociol. Sport 2012, 47, 526-530. [CrossRef]

13. Whisenant, W.A.; Pederson, P.M.; Obenour, B.L. Success and gender: Determining the rate of advancement for intercollegiate athletic directors. Sex Roles 2002, 47, 485-491. [CrossRef]

14. Colley, R.C.; Garriguet, D.; Janssen, I.; Craig, C.L.; Clarke, J.; Tremblay, M.S. Physical activity of Canadian children and youth: Accelerometer results from the 2007 to 2009 Canadian health measures survey. Health Rep. 2011, 22, 15-23.

15. Troiano, R.P.; Berrigan, D.; Dodd, K.W.; Mâsse, L.C.; Tilert, T.; McDowell, M. Physical activity in the United States measured by accelerometer. Med. Sci. Sports Exerc. 2008, 40, 181-188. [CrossRef]

16. Rotter, J. Generalized expectancies for internal versus external control of reinforcement. Psychol. Monogr. 1966, 80, 1-28. [CrossRef]

17. Arslan, C.; Dilmaç, B.; Hamarta, E. Coping with stress and trait anxiety in terms of locus of control: A study with Turkish university students. Soc. Behav. Personal. Int. J. 2009, 37, 791-800. [CrossRef]

18. Chang, C.Y.; Tsai, Y.M. Aerobic dance intervention on body image and exercise self- efficacy of college students in internal-external locus of control. J. Phys. Educ. Sports 2006, 16, 19-30.

19. Furnham, A.; Greaves, N. Gender and locus of control correlates of body image dissatisfaction. Eur. J. Personal. 1994, 8, 183-200. [CrossRef]

20. Adame, D.D.; Johnson, T.C.; Cole, S.P.; Matthiasson, H.; Abbas, M.A. Physical fitness in relation to amount of physical exercise, body image, and locus of control among college men and women. Percept. Mot. Ski. 1990, 70, 1347-1350.

21. Leonard, W.M., II. A Sociology Perspective of Sport; Macmillan: New York, NY, USA, 1998.

22. Snyder, E.E.; Spreitzer, E.A. Social Aspect of Sport; Prentice-Hall: Englewood Cliffs, NJ, USA, 1989.

23. Popenoe, D. Sociology; Prentice Hall: Englewood Cliffs, NJ, USA, 1999.

24. Allender, S.; Cowburn, G.; Foster, C. Understanding participation in sport and physical activity among children and adults: A review of qualitative studies. Health Educ. Res. 2006, 21, 826-835. [CrossRef]

25. Seabral, A.F.; Mendonca, D.M.; Thomis, M.A.; Peters, T.J.; Maia, J.A. Associations between sport participation, demographic and socio-cultural factors in Portuguese children and adolescents. Eur. J. Public Health 2007, 18, 25-30. [CrossRef]

26. Lin, T.E.; Liu, C.C.; Lee, C.H.; Tsai, F.H.; Chen, Z.M.; Lee, S.Y. A study of socialization into sport and motivations of athletes' participation sport. Natl. Pingtung Univ. Educ. Phys. Educ. 2012, 15, 394-406.

27. Chen, Y.H.; Chang, C.M.; Yang, M.H. The impact of sports socializing on sports participation behavior of junior high school students. NCYU J. Phys. Educ. Health Recreat. 2011, 10, 60-68.

28. Lin, H.L.; Huang, C.C.; Lee, C.Y. Empirical interpretation of female teacher participating in table-tennis experience. Natl. Taipei Univ. Educ. Phys. Educ. 2014, 9, 24-32.

29. Hung, C.W. The relationship between socialization and sports. Q. Chin. Phys. Educ. 2000, 14, 1-9.

30. Chang, S.M. An exploration of sports and socialization. Q. Chin. Phys. Educ. 1996, 10, 34-41.

31. Higginson, D.C. The influence of socializing agents in the female sport-participation process. Adolescence 1985, $20,73-82$.

32. Chien, Y.C. The application of IPA to examine the needs on exercise environment among the middle-aged and elder residents. Master's Thesis, National Pingtung University of Science and Technology, Pingtung, Taiwan, 2013.

33. Yang, Y.C.; Huang, Y.H.; Lee, T.H.; Chen, H.C.; Chang, C.J. Factors predicting the exercise participation in community-dwelling population. Taiwan Fam. Med. Res. 2005, 3, $29-41$.

34. Sallis, J.F.; Kerr, J. Physical activity and the built environment. J. Phys. Act. Health 2007, 4, 228-229. [CrossRef] 
35. Fox, K.R. Physical Self-Perception and Exercise Involvement. Ph.D. Thesis, Arizona State University, Phoenix, AZ, USA, 1987.

36. Chin, W.W. The partial least squares approach for structural equation modeling. In Modern Methods for Business Research; Marcoulides, G.A., Ed.; Lawrence Erlbaum Associates: Mahwah, NJ, USA, 1998; pp. 295-336.

37. Kock, N. Warp PLS 5.0 User Manual; Script Warp Systems: Laredo, TX, USA, 2015.

38. Crothers, L.M.; Kanyongo, G.Y.; Kolbert, J.B.; Lipinski, J.; Kachmar, S.P.; Koch, G.D. Job stress and locus of control in teachers: Comparisons between samples from the United States and Zimbabwe. Int. Rev. Educ. 2010, 56, 651-669. [CrossRef]

39. Wang, J.M. Prediction of coach's locus of control and players' goal orientation to coach's leadership behavior. Sports Exerc. Res. 2011, 13, 257-266.

40. Lu, C.F. A Study of the Effects of Internal-External Control Orientation and the Size of the Practice Target on the Performance of Table Tennis Forehand Stroke. Natl. Taiwan Univ. Phys. Educ. J. 1997, 1, 95-120.

41. Coleman, L.; Cox, L.; Roker, D. Girls and young women's participation in physical activity: Psychological and social influences. Health Educ. Res. 2007, 23, 633-647. [CrossRef]

42. Young, D.R.; Gittelsohn, J.; Charleston, J.; Felix-Aaron, K.; Appel, L.J. Motivation for exercise and weight loss among African-American women: Focus group results and their contribution towards program development. Ethn. Health 2001, 6, 227-245. [CrossRef]

43. Sharma, M.; Sargent, L.; Stacy, R. Predictors of leisure-time physical activity among African American women. Am. J. Health Behav. 2005, 29, 352-359. [CrossRef]

44. Tseng, S.W.; Hsieh, J.S. Residents' usage of neighborhood parks: A case study on Jingfeng Park, First Wanyo Park and Shinfeng Park in Taipei City. J. Agric. For. 2009, 6, $29-41$.

45. Vojnovic, I. Building communities to promote physical activity: A multi-scale geographical analysis. Geografiska Annaler: Series B. Hum. Geogr. 2006, 88, 67-90.

46. Liu, C.M.; Chao, K.Y.; Chou, C.C.; Lin, J.C. Active community environmental factors affecting residents' participation in physical activity. J. Phys. Educ. Sport Sci. 2010, 11, 11-22.

47. Duncan, M.J.; Spence, J.C.; Mummery, W.K. Perceived environment and physical activity: A meta-analysis of selected environmental characteristics. Int. J. Behav. Nutr. Phys. Act. 2005, 2, 11. [CrossRef]

48. Tsai, C.T.L. Media systems and their effects on women's sport participation in Taiwan. Sport Educ. Soc. 2009, 14, 37-53. [CrossRef]

49. Chen, C.C.; Liaw, Y.H.; Barnd, S. Cultural and Social Factors Affecting Women's Physical Activity Participation in Taiwan. Sport Educ. Soc. 2004, 9, 379-393. 